\title{
Food sharing and social cognition
}

\begin{tabular}{|r|l|}
\hline Journal: & WIREs Cognitive Science \\
\hline Manuscript ID: & COGSCI-516.R1 \\
\hline Wiley - Manuscript type: & Overview \\
\hline Complete List of Authors: & $\begin{array}{l}\text { Legg, Edward } \\
\text { Ostojic, Ljerka } \\
\text { Clayton, Nicky; University of Cambridge, Experimental Psychology }\end{array}$ \\
\hline Keywords: & Animals, Social cognition, Theory of mind, Cognitive primatology, Altruism \\
\hline $\begin{array}{r}\text { Choose 1-3 topics to } \\
\text { categorize your article: }\end{array}$ & Evolutionary Roots of Cognition (BAAB) < Cognitive Biology (BAAA) \\
\hline
\end{tabular}

SCHOLARONE $^{\text {m }}$

Manuscripts 
1 Food Sharing and Social Cognition

\author{
First author: \\ Name: Edward William Legg \\ Affiliation: Department of Psychology, University of Cambridge, Downing Street, CB2 \\ 3EB \\ Email: ewl24@cam.ac.uk
}

Second author: Full name and affiliation; plus email address if corresponding author Name: Ljerka Ostojić

Affiliation: Department of Psychology, University of Cambridge, Downing Street, CB2

3EB

Third author: Full name and affiliation; plus email address if corresponding author

Name: Nicola Susan Clayton

Affiliation: Department of Psychology, University of Cambridge, Downing Street, CB2

3EB

2

3 Abstract

4 Many non-human animals share food with each other, with kin, mates and other unrelated

5 individuals. When an individual shares food with another they lose a valuable resource. Thus,

6 traditionally much research has investigated how this behaviour can be an evolutionarily stable

7 strategy. Only recently has food sharing behaviour been exploited to investigate non-human

8 cognition. Certain evolutionarily stable strategies that have been proposed as accounts for food

9 sharing behaviours, such as reciprocity and interchange, may rely on complex cognitive abilities.

10 In these cases, an individual may calculate the benefit they may receive from sharing with the

11 recipient. In some species, sharing of food can facilitate the recipients' rate and extent of

12 learning. This form of teaching may be cognitively complex if the donor takes into account the

13 level of the recipient's abilities. In addition, an animal's food sharing behaviour, which in itself

14

15

16

17

18

19

20

21

22

23

24

25

26

27

28

29 may be based on a simple cognitive mechanism, could be used as a tool to investigate the extent to which the individual may be capable of complex cognitive abilities, for example, mental state attribution. These three areas of research: reciprocity, teaching and mental state attribution, illustrate how food-sharing behaviour can be used as a valuable natural behaviour to investigate cognition in non-human animals.

\section{Introduction}

Food sharing is a particularly amenable behaviour for investigating the social cognition of nonhuman animals because it tends to be a distinctly social behaviour and can be observed in a variety of species from insects to primates ${ }^{1,2}$. Food sharing in non-human animals can take active or passive forms. Active forms of food sharing involve the donor performing an action that provisions the recipient with a food item that the donor currently possesses. In primates active sharing can involve the 'handing' of food from one individual to another and in birds active sharing involves the passing of food between individuals' beaks. In contrast, passive forms of food sharing involve the non-monopolisation of a food source because an individual does not defend the food. Thus, passive forms of food sharing include 'tolerated theft' where a donor does not interfere when the recipient attempts to obtain food that is close by the donor ${ }^{3}$. 
Although there are cases where passive sharing may not be distinctly social the majority of the primate food sharing literature combines passive and active forms of sharing and we will use

32 food sharing to refer to both these forms.

33 Traditionally research has focused on the ultimate explanation of food sharing, namely, how this 34 behaviour can be part of an evolutionary stable strategy ${ }^{4,5}$. In line with these ultimate 35 explanations researchers have sought to understand the proximate mechanisms, including the psychological processes, which underlie these strategies. Some researchers claim that certain ultimate explanations of food sharing would require complex cognitive abilities ${ }^{6,7}$. As a consequence, food sharing behaviour has tended to be used for investigating only those psychological processes that have been directly implicated in producing an evolutionary stable strategy.

41 We suggest that there is also a second way in which the food sharing behaviours can be used to 42 test the cognitive mechanisms employed by non-human animals. Experimental techniques that employ natural behaviours are important because the animals are highly motivated to perform these behaviours and because they allow researchers to investigate particular cognitive mechanisms in ecologically valid contexts. Consequently, even if an individual's food sharing behaviour does not have cognitively complex underpinnings this behaviour can still be used as a tool to investigate aspects of cognition that are not directly related to food sharing. Thus, food sharing can be used in a similar way to how the imprinting of juvenile domestic chickens has been used to investigate their numerical and physical cognition ${ }^{8,9}$.

In this review we will discuss two cases in which food sharing behaviour may be directly reliant on sophisticated cognitive processes, namely reciprocity and teaching. We will then discuss recent research that has used food sharing behaviour as a tool to investigate mental state attribution.

\section{Reciprocity}

55 Reciprocity is an ultimate explanation of an animal's food sharing behaviour. It suggests that an 56 evolutionary stable strategy occurs because an individual can gain future benefits from sharing 57 either because they receive these benefits in kind (reciprocity $^{5}$ ) or in another commodity 58 (interchange ${ }^{10,11}$ ). Other benefits may accrue if sharing is used to indicate an individual's own 59 fitness or status to the donor and observers (costly signalling ${ }^{12}$ ). These three types of future benefits 60 are a consequence of the food sharing behaviour influencing an unrelated individual's behaviour 61 and could all be described as a form of reciprocity, albeit in the case of costly signalling in an 62 indirect sense $\mathrm{e}^{13}$. It should be noted that reciprocity describes one possible evolutionary stable 63 strategy of food sharing and that as such it is ambivalent about the proximate mechanisms 64 underlying the strategy.

65 Patterns of reciprocity (as an ultimate explanation) have been noted in a number of different 66 food sharing species. For instance, the amount of blood shared by vampire bats (Desmodus 67 rotundus), which share blood with individuals that have failed to forage, is correlated with the 68 amount of blood they have previously received from the recipient ${ }^{14,15}$. Moreover, the largest body 69 of research on food sharing and reciprocity has been conducted on chimpanzees; whose sharing 
70 behaviour has been hypothesised to be returned as increased coalitionary support ${ }^{16,17}$, increased 71 grooming ${ }^{18-20}$ or increased copulations with the recipient ${ }^{21,22}$.

72 However, evidence supporting these hypotheses in chimpanzees appears to vary depending on 73 the commodity reciprocated and the study population. Early observations on the chimpanzees at 74 Gombe indicated that males tended to share more with females in oestrous, suggesting that food 75 sharing may yield an immediate reproductive benefit ${ }^{21,22}$. Although a study on a captive 76 population of chimpanzees found that food sharing was correlated with copulations made in the time period surrounding the food sharing event ${ }^{23}$, recent work in Gombe and other wild populations found no evidence for this 'meat for sex' hypothesis when considering short term benefits $^{16,24,25}$. This contrasts with evidence supporting the 'food for grooming' hypothesis, because males share more with individuals that have recently groomed them ${ }^{19,20}$. There is evidence that long term benefits for food sharing can come from receiving increased copulations or from increased affiliative behaviours such as grooming ${ }^{26-28}$. For instance, a study on chimpanzees in the Tail forest found that food sharing was correlated with the number of copulations made by a dyad within the 22 month period of the study ${ }^{26}$. Thus, benefits that chimpanzees receive from food sharing may occur in the form of both short and long term interchanges and the timescale of the interchange may vary depending on the commodity.

However, it should also be noted that despite the correlations between commodities exchanged these studies may not satisfy the criterion for reciprocity because the correlations could be the result of a third factor. For instance, a field study by Gilby $^{24}$ revealed a link between grooming and food sharing on a superficial level. Critically, this link was mediated by harassment; females that had groomed a male gained more food and harassed him at greater frequencies than females that had not groomed him. Consequently, this pattern of behaviour does not satisfy the criterion for reciprocity, Moreover, from a proximate perspective the temporal contiguity between the sharing event and the benefit make it plausible that this behaviour could be learnt through instrumental conditioning (the lack of temporal contiguity in actual cases of reciprocity make this a less plausible explanation of the animals behaviour $)^{29}$.

The requirement for reciprocity (as an ultimate explanation) to involve a behaviour that brings no immediate evolutionary benefit to an individual is often, mistakenly, considered to mean that the proximate mechanism behind such behaviour must necessarily take into account this future benefit $^{30-32}$. Of the three main hypothesised proximate mechanisms that can account for reciprocity and interchange only one of them requires individuals to take into account the future benefit of their behaviour, namely calculated reciprocity. In the following sections we will discuss the cognitive requirements of the three proximate mechanisms that have been hypothesised to underlie reciprocity before turning to the evidence for these proximate mechanisms.

\section{Calculated Reciprocity}

106 Calculated reciprocity accounts for an animal performing a costly action, such as food sharing, 107 on the basis of calculating the future benefit of that action ${ }^{18}$. From a psychological perspective 108 this mechanism presents the most cognitively demanding explanation of reciprocity ${ }^{33,34}$. 
111 individuals would need to be able to quantify the commodities reciprocated in order to assess

112 their debt and credit to other individuals ${ }^{2}$. The set of cognitive abilities required for calculated

113 reciprocity has been argued to make it unlikely that this proximate mechanism accounts for many

114 food sharing behaviours ${ }^{7}$.

\section{Attitudinal Reciprocity}

116 Attitudinal reciprocity suggests that individuals are likely to share more with individuals who they

117 have a positive attitude towards. This attitude is influenced by previous positive and negative

118 interactions with specific individuals ${ }^{35,36}$. Notably because attitudinal reciprocity does not entail

119 representing the value of a future benefit there is no need for a donor to resist temporal

120 discounting. It has also been argued that the attitudinal view reduces the memory load on an

121 individual because they do not have to encode the precise nature of their interactions with an

122 individual because this is quantified by a change in attitude ${ }^{34}$.

123

124

125

126

127

128

129

130

131

132

133

134

135

136

137

However, there remains an open-question over the time-scale over which the 'attitude' that influences reciprocity operates. One school of thought implies that these attitudes only operate over a short scale of time and would at most take into account the last few interactions between the donor and the recipient ${ }^{34,35,37}$. A second school of thought suggests that these attitudes accumulate over a large time period based on multiple interactions and that for familiar individuals recent negative interactions may be overridden by the accumulation of previous positive ones $^{32}$.

\section{Symmetry based reciprocity}

An even simpler proximate mechanism behind reciprocal food sharing suggests that an individual randomly distributes food to other individuals (regardless of previous interactions) ${ }^{18}$. This will eventually lead to each individual performing similar amounts of food sharing with each other if they are within a closed group. However, this symmetry-based reciprocity ${ }^{18}$ is prone to being infiltrated by cheats who take advantage of this propensity and is unlikely to have evolved as an evolutionary stable strategy ${ }^{32}$.

\section{Generalized reciprocity}

139 Generalised reciprocity suggests that animals are more likely to share food if they have had a 140 positive interaction with any other individual regardless of who the recipient is. Whereas 141 symmetry based reciprocity is likely to be limited to closed groups generalised reciprocity can account 142 for reciprocity within open groups in which individuals are mobile and can move between 143 groups $^{38}$. Models suggest that such reciprocity can occur if individuals tend to perform positive 144 behaviours after any individual has performed a positive behaviour toward them and if the 145 individuals can 'walk away' from a group in some cases where they have not experienced a 146 positive behaviour. Critically, this leads to groups breaking up if there is an influx of cheats, 147 ensuring that there tends to be reciprocation within the group. This kind of reciprocity is reliant 148 on minimal cognitive requirements as it does not necessitate individual recognition because the 149 identity of the donor is irrelevant to which member of the group receives a positive action from 150 the recipient in return ${ }^{39}$. 
152 Evidence demonstrating specific proximate mechanisms behind reciprocal food sharing is 153 sparse. In part this is due to research focusing on the ultimate mechanisms of food sharing 154 behaviour. Thus, although there are a number of studies that show correlations indicating a 155 reciprocal pattern of exchange, these studies cannot reveal the proximate mechanism underlying 156 this reciprocation.

157 Attitudinal reciprocity, at least in its short term form as proposed by de Waal ${ }^{35,36}$ is thought to be characterised by co-fluctuations in the amount of food shared by individuals in a dyad over a short time period. This co-fluctuation of food exchange is predicted because if an individual is taking into account the immediate previous interactions of an individual they will start to reduce the amount they share when that individual reduced the amount they shared. Evidence of such short term co-fluctuations in sharing behaviour have been shown in capuchin monkeys' and bonobos' food sharing behaviour while longer term correlations have been shown in vampire bats and chimpanzees ${ }^{15,27,35}$.

165 Few studies have claimed to demonstrate calculated reciprocity. A notable exception is the result 166 of an orang-utan token exchange task. Dufour et al (2009) ${ }^{40}$ suggested that calculated reciprocity 167 could be shown by demonstrating that a donor shares items that are valuable to the recipient but 168 not to themselves and that the donor adapts their sharing behaviour based on the recipients 169 sharing behaviour. Notably, generous donors should share less when the recipient tends to 170 transfer items infrequently and a donor that is initially less generous than the recipient should increase their rate of sharing to maintain high levels of transfer with the recipient. Consequently, two orang-utans who had been trained to exchange tokens with a human in return for food were positioned in two adjacent cages and were able to exchange tokens between each other and with the experimenter. In the critical stages of the experiment 24 tokens were placed in each compartment, all 24 of the tokens were valueless to the occupant of the compartment but 12 of the tokens could be exchanged by the orang-utan in the adjacent compartment for food. In the initial series of trials one individual shared more items than the other individual. However, in subsequent trials the rate of transfers converged and there were correlations between the number of valuable items shared and received in all but the very first session. Furthermore, these exchanges were characterised by turn-taking between the individuals.

However, it should be apparent that the results of the orang-utan token exchange experiment could also be achieved if attitudinal reciprocity or generalised reciprocity was being employed. The convergence of each individual's rate of sharing may be explained by changes in attitude or overall tendency to share (as predicted by generalised reciprocity) induced by the lower or higher rate of the other individuals sharing. The correlations found in all but the first session demonstrate co-fluctuations in the amount individual's share - an effect that has been taken as evidence of attitudinal reciprocity. Moreover, the other result that the authors claim indicates calculated reciprocity, namely turn taking, has also been noted in other forms of exchange and in these cases is not thought to involve complex cognition ${ }^{41}$. It is also unclear what to make of the turn-taking behaviour of this single dyad because without the ability to investigate partner choice generalised reciprocity is difficult to rule out. Moreover, other studies have failed to find such turn taking in orang-utans ${ }^{42}$. 
193 Furthermore, co-fluctuation in sharing behaviours need not be explained by attitudinal

194 reciprocity or calculated reciprocity. Instead this pattern could be the result of an external factor

195 that exerts the same influence on the food sharing behaviour of each individual within a dyad.

196 For instance, if the amount of food shared by an individual is linked to light levels or time of day 197 then because both individuals are exposed to this same factor the quantities that they share are 198 likely to fluctuate. Moreover, absence of such co-fluctuation may be the result of the longer term 199 form of attitudinal reciprocity where a recent negative or positive interaction with an individual 200 may have minimal influence on the emotional score they have gained from other interactions ${ }^{32}$.

\section{$201 \quad$ Future directions}

202 Current research that investigates fluctuations in sharing behaviour without actively manipulating an individual's rate of sharing cannot easily distinguish between the three major proximate mechanisms of reciprocity. Symmetrical reciprocity makes a clear prediction that an individual's own rate of sharing should not be influenced by a recipient's rate of sharing. As such experimental manipulations of the recipient's rate of sharing should not influence the donor's rate of sharing and if these rates do vary then the subject is engaging in either attitudinal or calculated reciprocity. Note that relying on natural variations in the rates of sharing gives rise to the possibility that both individuals' rates of sharing are influenced by an external variable.

A harder task is to foresee where the predictions of the sharing behaviours expected from attitudinal and calculated reciprocity diverge. We see two possible ways in which such a distinction could be made. Firstly, attitudinal reciprocity should be immune to the constraints imposed on calculated sharing by the need to resist temporal discounting. Secondly, calculated reciprocity should be immune to any experimental manipulations of the subject's attitude toward an individual. Until studies begin to manipulate these constraints it remains impossible to definitively demonstrate that reciprocal food sharing behaviours are based on anything other than symmetrical reciprocity.

\section{Teaching}

Teaching in non-human species is typically considered on a functional rather than a mechanistic basis $^{43,44}$. Therefore, evidence of teaching need not implicate the sophisticated cognitive mechanisms that can underlie human pedagogy ${ }^{45,46}$. Reflecting this approach Caro and Hauser's ${ }^{43}$ commonly cited definition of teaching in non-human animals is concerned with i) whether an actor modifies their behaviour in the presence of a naïve individual (at a cost to themselves), ii) whether this modification exerts an influence on the naïve individual, and iii) whether this results either in the naïve individual learning a new skill or influences the rate or efficiency with which the naive individual acquires the skill ${ }^{43}$. Although there are a limited number of examples of teaching in the wild a large proportion of these examples involve parents sharing food with their offspring. Parent-offspring food sharing may be a particularly fruitful context for investigating teaching behaviours because sharing food with naive infants can provide them with the opportunity to learn about what is edible and how certain, difficult-to-handle, foods can be $\operatorname{accessed}^{47,48}$.

Food sharing has been proposed to increase the breadth of infant's knowledge about which food is edible ${ }^{49}$ Within primates the callitrichids, a family that includes tamarins and marmosets, are 
atypical because of the large quantity of food infants obtain from parental sharing behaviour. results. One study on Tamarins has showed that they increased the amount of novel foods they shared with infants and one study has not found this effect ${ }^{50,51}$. Moreover, a study on common marmosets (Callithrix jacchus) that manipulated the novelty and palatability of food items found that parents did not facilitate the dietary choices of their infants by selectively exposing them to novel food items and that parents actually shared unpalatable novel food with the infants at the highest rate ${ }^{52}$.

Despite the lack of evidence that food sharing can add to what infants know to be edible there is evidence that food sharing can allow infants to gain skills about how to access or obtain difficultto-handle food. Animals can acquire skills through observing the products of another's actions, either because the actions have made the task easier or because the effect draws attention to a key stimulus ${ }^{53,54}$. There is evidence that this form of teaching may occur in some carnivorous species with parents releasing dead or maimed prey for their infants to hunt - this might provide the opportunity for the infants to hone their hunting skills. For instance, there is anecdotal evidence that raptors such as ospreys (Pandion haliaetus) display this type of behaviour, by dropping fish for their young to catch. Moreover, observational studies on felids indicate that they release prey to offspring and that experimentally provisioning prey to the kittens of domestic cats (Felis silvestris catus) improves their ability to hunt ${ }^{55-58}$. There is also strong evidence of this behaviour in meerkats, which we will return to later ${ }^{59}$.

A further example of a behaviour that satisfies the functional definition of teaching has been observed in the pied babbler (Turdoides bicolor). During parent-offspring food sharing bouts babblers produce purr calls. These calls are costly because parents that produce a greater number of purr calls have reduced weight; unlike in other species the calls do not increase the efficiency of the sharing bout ${ }^{60}$. Importantly, the frequency of these food calls increases as the chicks near fledging age. The contingency between calls and shared food has the effect of conditioning the chicks to associate these calls with food ${ }^{60}$. These food calls are then used by the parents in the post-fledging period to recruit their young to novel foraging locations ${ }^{61}$. Thus, unlike the other forms of food sharing discussed here, which provide infants with experience about a particular food, food sharing in pied babblers provides infants with the opportunity to learn an association between their parents' purr call and the presence of food.

These food sharing behaviours can also be experimentally tested to investigate which cognitive mechanisms may underlie the teaching behaviour. Theoretically distinguishing cognitively demanding teaching from less cognitively demanding teaching has proven controversial and this is partly due to questions about what constitutes teaching in humans ${ }^{44,45}$. For the purpose of this review we distinguish between ability based teaching and harmonised teaching (note that these terms are not typically used within the literature but offer an apt description of the proximate mechanisms behind teaching in non-human animals).

\section{Ability Based Teaching}

Ability based teaching requires the tutor to alter the type of food they share with their pupil based on the pupils ability. Critically, teachers should be able to detect deficiencies in the pupil's ability 
275 and make steps to alter their behaviour appropriately ${ }^{46}$. Thus, even if a tutor's behaviour is 276 primarily reliant on a single cue that indicates their pupil's ability they should be able to detect 277 deficiencies from other cues. Byrne and Rappaport $(2011)^{46}$ give an example in which a school 278 teacher starts giving a lesson to a class based on the average knowledge of like-aged pupils 279 without gauging the abilities of individual students but if necessary the teacher can still recognise 280 if a student is struggling and adjust their teaching appropriately.

From a cognitive perspective this level of sensitivity to a pupil's ability requires recognising how well another individual can perform an action. Moreover, in cases where teaching aims to increase a pupil's knowledge, such as increasing their dietary breadth, it would be necessary for the tutor to keep track of what the pupil has or has not had experience of. In cases where teaching aims to increase a pupil's physical ability tutors may need to recognise the intentions behind the pupil's failed actions. Evidence for such abilities outside of the context of teaching would appear to be limited to certain primates and corvids ${ }^{62-64}$.

\section{Harmonised Teaching}

In harmonised teaching a teacher's behaviour maps onto a pupil's changing ability because of stereotyped responses to a single cue. For instance, Caro and Hauser (1992) suggest that teaching could occur if a mother altered her behaviour in a stereotyped time course that was dependent on her own hormonal changes from birth. Critically, harmonised teaching can be distinguished from ability based teaching because it relies on a stereotyped response to a single cue which could lead to mothers mistakenly changing their teaching behaviour if this cue was not in line with their pupil's ability, an effect that is unlikely to occur in ability based teaching.

Outside of the food sharing context this form of teaching has been shown in ants, which are unlikely to possess the cognitive mechanisms necessary for ability based teaching. These ants run in tandem toward a food source and a knowledgeable leader will wait for a naïve follower. This behaviour is likely to be a result of a hard-wired slowing response when the leader is at a certain distance from the follower ${ }^{65}$.

\section{Evidence for the proximate mechanisms of teaching}

Evidence of teaching via food sharing behaviour is relatively rare and the precise mechanism behind such behaviours has only been investigated in detail in one species, meerkats ${ }^{59}$.

Meerkats are cooperative breeders, and tend to form groups of around 15 individuals with the dominant pair being the primary reproducers ${ }^{66,67}$. Food is shared with infants by conspecific helpers ${ }^{68}$. The shared food tends to consist of invertebrates and the quantity of the food shared is linked to the offspring's life time reproductive success ${ }^{69}$. A significant proportion of an adult meerkat's diet consists of scorpions that contain potent neurotoxins and scorpions that aggressively defend themselves ${ }^{70}$. These scorpions are also shared with offspring and helpers typically provision dead scorpions or scorpions with the sting removed ${ }^{59}$. Critically, the frequency with which dead or disabled scorpions are shared with infants decreases with the age of the infant. Experimental manipulations of the type of scorpions provided to offspring indicate that infant meerkats who had previously received live scorpions to handle are more successful or faster at handling scorpions than infants that had previously received dead scorpions or infants 
that had received a quantity of boiled egg equivalent in weight to the scorpions provided to the other infants.

Critically, the changes in the items shared with infants are mediated by changes to the infants' that has young infants helpers provision a greater proportion of intact scorpions than after hearing playbacks of young infants ${ }^{59}$. The results of the auditory playbacks indicate that the meerkats are likely to be showing a hard-wired response to the infants' begging calls rather than considering the infants' actual abilities which implicates harmonised teaching.

\section{Future directions}

Important questions remain about which cognitive mechanisms can explain the teaching behaviour of animals. Teaching in humans often requires a sensitivity to the level of the pupil's knowledge and ability ${ }^{71}$. It has been suggested that such sensitivity does not underlie meerkats' teaching behaviour because they respond stereotypically to auditory playbacks of infants' begging calls. However, these playbacks were conducted in a single experimental session and if the helpers primarily rely on auditory information about the infants' abilities then this stereotyped response is unsurprising because they had limited opportunity to receive feedback that their primary indicator of the infants' ability was incorrect. Consequently, it would be important to establish whether helpers adjust their sharing behaviour when they are repeatedly presented with auditory information that conflicts with the infants' actual ability. If the meerkats are sensitive to the infants' ability then under these cases of repeated exposure the helpers should adjust their sharing behaviour. A similar test is required to establish whether pied babblers are sensitive to their infants' ability to pair the purr call with receiving food. Infants that have learnt that receiving food and purr calls are associated beg more when purr calls are played. If parents are sensitive to how well the chicks have learnt the contingency then they should modulate the frequency with which they pair calls and food sharing based on the chicks begging behaviour to their purr calls.

These studies suggest that food sharing behaviour can play an important role in the transmission of information between generations. However, due to the limited number of experiments indicating teaching behaviour in non-human animals and the uncertainty surrounding the mechanisms that underlie each of these abilities further experiments are necessary to establish the cognitive mechanisms that underpin the use of food sharing as a form of teaching.

\section{Mental State Attribution}

One of the questions raised by evidence of teaching in non-human animals is whether or not the teachers are sensitive to their pupil's knowledge. Sensitivity to others' knowledge is part of a special form of social cognition concerned with the attribution of internal mental states to others, namely Theory of Mind ${ }^{72,73}$. Humans are able to accurately predict another's actions by attributing mental states such as beliefs and desires to them. Critically, Theory of Mind would require animals to distinguish their own mental states from another's (self-other differentiation) and to account for the representational nature of these mental states (beliefs represent reality, desires represent the desired outcome). Food sharing can be used to investigate these factors because many species are motivated to share high quality food, i.e. food that the donor desires. 
Self-other differentiation can be tested by investigating whether donors can cater to the desires of a recipient that differ to their own desire. Moreover, a donor's ability to account for the representational nature of desires can be tested by investigating whether they can account for the differences in two individuals' desires or changes to the same individual's desire. However, in non-human animals, distinguishing the ability to attribute mental states from a simpler cognitive mechanism has proven difficult. Critically, mental states cannot be directly observed but must instead be inferred from observations of behaviours or situations that cause particular mental states or deduced from observing the effect of a mental state ${ }^{74}$. Consequently, research cannot easily distinguish cases in which an animal attributes a mental state from cases in which the animal responds to the behaviour of an individual without attributing a mental state (behaviour reading $)^{75,76}$. Different forms of behaviour reading could explain an animal's ability to share desirable food with a recipient. For instance, a donor may share if the recipient is begging for food. Critically, the donor need not attribute a desire to recognise that he should share in this context. Thus, tests of Theory of Mind on non-human animals must not only test for self-other differentiation and the ability to account for the representational nature of mental states, they must also control and rule out behaviour reading as an alternative explanation ${ }^{77,78}$. The food sharing behaviour of non-human animals allows for these alternative explanations to be empirically investigated by manipulating the donor's and recipient's desires and the way in which donors are informed of the recipient's desire ${ }^{79}$. To date the only research that exploits the food sharing behaviour in the context of Theory of Mind has been conducted on corvids.

\section{Desire State Attribution: Eurasian jays}

377 During their breeding season male Eurasian jays (Garralus glandarius) actively share high quality 378 food with their female partners. This behaviour has been used to investigate whether the male jay can share food that is in line with the female's current desire as manipulated through specific satiety. Specific satiety refers to the devaluation for a particular food after being sated on it ${ }^{80-82}$. In the first study that investigated the cognitive mechanism behind the male's sharing behaviour, the male was fed on the jays' maintenance diet (MD), while he saw his female partner being fed on either MD, wax moth larvae (W) or mealworm beetle larvae (M). These three conditions were run on separate days. This meant that when the female had been fed on MD her desire was neutral, whereas when she had been fed $\mathrm{W}$ she had a greater desire for $\mathrm{M}$ and when she had been prefed $\mathrm{M}$ she had a greater desire for $\mathrm{W}$. In the subsequent test phase, the male was given 20 choices between a single $\mathrm{W}$ or $\mathrm{M}$ which he could choose to eat, cache or share with the female. The larvae types the male chose to share were in line with his partner's desire: he shared a higher proportion of $\mathrm{W}$ when she was sated on $\mathrm{M}$ than when she was sated on $\mathrm{W}^{83}$, indicating that the male Eurasian jay catered for his partner's desire.

Furthermore, two alternative explanations of this result have been ruled out. The first is that the male did not differentiate between his own desire and his partner's desire, i.e. that he did not demonstrate self-other differentiation. This explanation suggests that the male changed the food he shared with his partner because his own desire for the two food types was influenced by having watched his partner eat one food type to satiety. However, when the male was not able to share, the food he ate did not vary based on what the female had eaten. Thus the female's desire did not influence the male's own desire for the foods. The second alternative explanation of the male's behaviour is that he used a behavioural indication at the time of sharing to respond to the 
female's desire. Such a direct response to a behaviour would be considered a form of 'stimulus bound behaviour reading ${ }^{76}$. However, the male's use of behavioural indications at the time of sharing was ruled out by an experiment in which the female was fed out of sight of the male such that he did not know what she was sated on. Here, the only way in which the male could cater for his partner's desire was if he relied on some form of indication of her desire. The results showed that the male was unable to do so, suggesting that the male's sharing behaviour was not a result of 'stimulus bound behaviour reading'.

A further study, in which both the male's and female's desires were manipulated by specific satiety, has investigated whether the male jay can disengage from his own desire to cater for his partner's desire ${ }^{84}$. In this experiment the desire of the male was manipulated by sating him on either W or M and the female's desire either matched the male's own desire (e.g. she was sated on $\mathrm{W}$ when he was sated on W: matched condition), was neutral (she was fed MD on both days: neutral condition) or was in conflict with the male's own desire (e.g. she was sated on W when he was sated on M: conflicting condition). Although the male could disengage from his own desire to cater for his partner's conflicting desire, his response was biased in comparison to the matched and neutral conditions. Critically, this result reflects studies of biases on adult humans' Theory of Mind which provide evidence that adults' judgements of others' motivations are biased by their own motivational state ${ }^{85}$. There is further evidence that adults make more errors when judging another person's belief that differs to their own than when making equivalent judgements about their own memory or when following an arbitrary rule ${ }^{86,87}$. Thus, evidence that the male jay is biased by his own current desire state when catering for his partner's desire state indicates that a similar process may govern the attribution of mental states in Eurasian jays and humans.

\section{Future directions}

423 These studies present a novel way of testing mental state attribution through the use of food 424 sharing and by manipulating the donor's and recipient's desires. While the current findings rule out the possibility that the male jay relies on 'stimulus bound behaviour reading', further tests are necessary to test for other behaviour reading explanations of the jay's behaviour. The male's behaviour could be based on him having observed a particular behaviour exhibited by his partner during the feeding phase of the experiment, for instance the male might be reliant on observing his partner reject the food that she is sated on $^{88}$. This could be tested by comparing the male's response to their partner's food rejection behaviour with their response when the female is given just enough food to be sated such that she rejects no food at all. It would also be possible to present a scenario where the male does not actually see his partner's eating behaviour but instead has to infer what his partner has eaten from seeing what food was initially provided to her ${ }^{89}$. A further way of alleviating behaviour reading explanations is to demonstrate the flexibility of the individual's response. While the hypothetical experiments described above would demonstrate that the male responds to disparate cues indicating his partner's desire they are both reliant on specific satiety. Thus, an important test of the cognitive mechanism behind the jays' food sharing behaviour would be to demonstrate that the males can cater for their partner's desire in circumstances other than those induced through specific satiety. For instance, if a male observed a female choosing to eat a single $\mathrm{W}$ over a single $\mathrm{M}$, would he attribute that she desired $\mathrm{W}$ (note 
441 that this attribution is in the opposite direction to the effect of specific satiety where the female 442 eating multiple $\mathrm{W}$ would lead to her desiring $\mathrm{M}$ )? In addition, the food sharing behaviour of 443 other species could be used to investigate whether desire attribution in this context is only 444 exhibited by Eurasian jays, or whether the ability is present in other large brained birds such as 445 corvids and parrots, and whether food- sharing primates also possess this ability.

446 It may also prove possible to use the food sharing behaviours of primates in a similar manner. A 447 recent study showed that capuchin monkeys protected their food more after seeing another 448 eating $^{90}$. Whether this result is a consequence of capuchin's food protection behaviours being 449 triggered after observing another's eating behaviour or a more sophisticated ability remains to be 450 tested.

\section{Conclusions}

452 This review has discussed whether there is any evidence linking the food sharing behaviour of 453 non-human animals with complex cognitive abilities. Critically, we have discussed evidence that 454 food sharing behaviour may or may not be (i) beneficial to the donor, (ii) important for 455 recipients' learning, and (iii) based on the attribution of desires to the recipient. However, it is 456 clear that currently there is limited empirical evidence linking specific cognitive mechanisms with 457 these outcomes and that further research is necessary to better establish the cognitive 458 foundations of these behaviours. This future research will complement the large body of 459 research that has considered the ultimate mechanisms behind food sharing.

460 The fact that complex cognition may not underlie food sharing itself should not put researchers 461 off using this behaviour as a tool for investigating complex cognitive abilities. Just as imprinting 462 has been used to investigate the cognitive abilities of domestic chickens ${ }^{8,9}$, food sharing could be 463 used to investigate the cognitive abilities of a wide variety of animals. The use of the Eurasian 464 jays' food sharing behaviour to investigate whether they attribute mental states reflects such an 465 approach. Future experiments on other species could investigate other sophisticated cognitive 466 abilities For example, if a species has a sharing patterns that follows a specific order, such as 467 rooks $^{91}$, which only share with subordinate conspecifics, it would be possible to test whether 468 individuals are surprised by sharing events that happen in the wrong direction and whether they 469 can use transitive inference to recognise a novel conspecific's position in the hierarchy ${ }^{92}$. In 470 summary, current studies have only touched the surface of what could be investigated using the 471 food sharing behaviour of non-human animals and further exploitation of this behaviour might 472 produce important insights into non-human cognition.

\section{References}

474 1. Vahed K. The function of nuptial feeding in insects: a review of empirical studies. Biol Rev $475 \quad$ Camb Philos Soc. 1998;73(01):43-78.

476 2. Stevens JR, Gilby IC. A conceptual framework for nonkin food sharing: timing and 477 currency of benefits. Anim Behav. 2004;67(4):603-614. doi:10.1016/j.anbehav.2003.04.012. 
480 4. Hamilton W. The genetical evolution of social behaviour. I. J Theor Biol. 1964.

481 5. Trivers RL. The Evolution of Reciprocal Altruism. Q Rev Biol. 1971;46(1):35-57.

482

483

484

485

486

487

488

489

490

491

492

493

494

495

496

497

498

499

500

501

502

503

6. Stevens JR, Cushman F a., Hauser MD. Evolving the Psychological Mechanisms for Cooperation. Annu Rev Ecol Evol Syst. 2005;36(1):499-518. doi:10.1146/annurev.ecolsys.36.113004.083814.

7. Stevens JR, Hauser MD. Why be nice? Psychological constraints on the evolution of cooperation Why be nice? Psychological constraints on the evolution of cooperation. Trends Cogn Sci. 2004;8(2):60-5. doi:10.1016/j.tics.2003.12.003.

8. Chiandetti C, Vallortigara G. Intuitive physical reasoning about occluded objects by inexperienced chicks. Proc Biol Sci. 2011;278(1718):2621-7. doi:10.1098/rspb.2010.2381.

9. Rugani R, Regolin L, Vallortigara G. Rudimental numerical competence in 5-day-old domestic chicks (Gallus gallus): identification of ordinal position. J Exp Psychol Anim Behav Process. 2007;33(1):21-31. doi:10.1037/0097-7403.33.1.21.

10. Hemelrijk CK. A Matrix Partial Correlation Test used in Investigations of Reciprocity and Other Social Interaction Patterns at Group Level. 1990.

11. Hemelrijk CK, Ek A. Reciprocity and interchange of grooming and "support" in captive chimpanzees. Anim Behav. 1991;41(6):923-935. doi:10.1016/S0003-3472(05)80630-X.

12. Zahavi A. Reliability in communication systems and the evolution of altruism. In: Stonehouse B, Perrins CM, eds. Evolutionary Ecology. London: Macmillan Press; 1977:253260.

13. Nowak M a, Sigmund K. Evolution of indirect reciprocity. Nature. 2005;437(7063):12918. doi:10.1038/nature04131.

14. Wilkinson G. Reciprocal food sharing in the vampire bat. Nature. 1984.

15. Carter GG, Wilkinson GS. Food sharing in vampire bats $\square$ : reciprocal help predicts donations more than relatedness or harassment. Proc R Soc B Biol Sci. 2013;280.

16. Mitani JC, Watts DP. Why do chimpanzees hunt and share meat? 2001;(Stanford 1998):915-924. doi:10.1006/anbe.2000.1681.

17. Nishida T, Hasegawa T. Meat-sharing as a coalition strategy by an alpha male chimpanzee. Top Primatol. 1992;1:159-174.

18. de Waal FBM, Luttrell LM. Mechanisms of Social Reciprocity in Three Primate Species: Symmetrical Relationship Characteristics or Cognition? Ethol Sociobiol. 1988;9:101-118.

19. de Waal FBM. The chimpanzee's service economy: Food for grooming. Evol Hum Behav. 1997;18:375-386.

20. de Waal FBM. Food sharing and reciprocal obligations among chimpanzees. J Hum Evol. 1989;18:433-459. 
515 21. Stanford C. Chimpanzee and red colobus: the ecology of predator and prey. Cranbury, New Jersey: Associated University Press; 1998.

517

518

519

520

521

522

523

524

525

526

527

528

529

530

531

532

533

534

535

536

537

538

539

540

541

542

543

544

545

546

547

548

549

550

22. Teleki G. The predatory behavior of wild chimpanzees. Cambridge, MA: Havard University Press; 1973.

23. Crick J, Suchak M, Eppley TM. The roles of food quality and sex in chimpanzee sharing behavior ( Pan troglodytes ). 2013;150:1203-1224. doi:10.1163/1568539X-00003087.

24. Gilby IC. Meat sharing among the Gombe chimpanzees: harassment and reciprocal exchange. Anim Behav. 2006;71(4):953-963. doi:10.1016/j.anbehav.2005.09.009.

25. Gilby IC, Emery Thompson M, Ruane JD, Wrangham R. No evidence of short-term exchange of meat for sex among chimpanzees. J Hum Evol. 2010;59(1):44-53. doi:10.1016/j.jhevol.2010.02.006.

26. Gomes CM, Boesch C. Wild Chimpanzees Exchange Meat for Sex on a Long- Term Basis. PLoS One. 2009;4(4):16-18. doi:10.1371/journal.pone.0005116.

27. Jaeggi A V, Groot E De, Stevens JMG, Schaik CP Van. Evolution and Human Behavior Mechanisms of reciprocity in primates: testing for short-term contingency of grooming and food sharing in bonobos and chimpanzees. Evol Hum Behav. 2013;34(2):69-77. doi:10.1016/j.evolhumbehav.2012.09.005.

28. Muller MN, Mitani JC. Conflict and Cooperation in Wild Chimpanzees. Adv Study Behav. 2005;35:276-331. doi:10.1016/S0065-3454(05)35007-8.

29. Rescorla RA, Holland PC. Behavioral Studies of Associative Learning in Animals. Annu Rev Psychol. 1982;33(1):265-308. doi:10.1146/annurev.ps.33.020182.001405.

30. Schino G, Aureli F. A few misunderstandings about reciprocal altruism. Commun Integr Biol. 2010;3(6):561-3. doi:10.4161/cib.3.6.12977.

31. West S a, Griffin a S, Gardner a. Social semantics: altruism, cooperation, mutualism, strong reciprocity and group selection. J Evol Biol. 2007;20(2):415-32. doi:10.1111/j.14209101.2006.01258.x.

32. Schino G, Aureli F, Di I, Tecnologie SE, Cognizione D. Reciprocal Altruism in Primates $\square$ : Partner Choice, Cognition, and Emotions. 2009;39(09):45-69. doi:10.1016/S0065-3454(09)39002-6.

33. Brosnan SF, de Waal FBM. A proximate perspective on reciprocal altruism. Hum Nat. 2002;13(1):129-152.

34. De Waal FBM, Brosnan SF. Simple and complex reciprocity in primates. 2005:79-100.

35. De Waal FBM. Attitudinal reciprocity in food sharing among brown capuchin monkeys. Anim Behav. 2000;60:253-261. doi:10.1006/anbe.2000.1471.

36. De Waal FBM, Suchak M. Prosocial primates: selfish and unselfish motivations. Philos Trans R Soc Lond B Biol Sci. 2010;365(1553):2711-22. doi:10.1098/rstb.2010.0119. 
37. De Waal FBM, Suchak M. Prosocial primates $\square$ : selfish and unselfish motivations Prosocial primates $\square$ : selfish and unselfish motivations. 2010;(August). doi:10.1098/rstb.2010.0119.

38. Hamilton IM, Taborsky M. Contingent movement and cooperation evolve under generalized reciprocity. Proc Biol Sci. 2005;272(1578):2259-67. doi:10.1098/rspb.2005.3248.

39. Pfeiffer T, Rutte C, Killingback T, Taborsky M, Bonhoeffer S. Evolution of cooperation by generalized reciprocity. Proc Biol Sci. 2005;272(1568):1115-20. doi:10.1098/rspb.2004.2988.

40. Dufour V, Pelé M, Neumann M, Thierry B, Call J. Calculated reciprocity after all $\square$ : computation behind token transfers in orang-utans Calculated reciprocity after all $\square$ : computation behind token transfers in. 2009;(December 2008). doi:10.1098/rsbl.2008.0644.

41. Fischer EA. Mating behavior in the black hamlet — gamete trading or egg trading? Environ Biol Fishes. 1987;18(2):143-148. doi:10.1007/BF00002602.

42. Pele M, Thierry B. Token Transfers Among Great Apes (Gorilla gorilla , Pongo pygmaeus , Pan paniscus , and Pan troglodytes ): Species Differences, Gestural Requests , and Reciprocal Exchange. 2009;123(4):375-384. doi:10.1037/a0017253.

43. Caro TM, Hauser MD. Is There Teaching in Nonhuman Animals? Q Rev Biol. 1992;67(2):151-174.

44. Thornton A. Teachers in the wild: some clarification. Trends Cogn Sci. 2007;11(7):272-273. doi:10.1016/j.tics.2007.05.006.

45. Csibra G. Teachers in the wild. 2007;11(3):95-96. doi:10.1016/j.tics.2006.11.010.

46. Byrne RW, Rapaport LG. What are we learning from teaching? Anim Behav. 2011;82(5):1207-1211. doi:10.1016/j.anbehav.2011.08.018.

47. Rapaport LG, Brown GR. Social influences on foraging behavior in young nonhuman primates: Learning what, where, and how to eat. Evol Anthropol Issues, News, Rev. 2008;17(4):189-201. doi:10.1002/evan.20180.

48. Brown GR, Almond REA, van Bergen Y. Begging, stealing and offering: food transfer in non-human primates. Adv Study Behav. 2004;34:265-295.

49. Ewer R. The behaviour of the meerkat, Suricata suricatta (Schreber). Z Tierpsychol. 1963:570-607.

50. Rapaport LG. Provisioning of young in golden lion tamarins (Callitrichidae, Leontopithecus, rosalia): a test of the information hypothesis. Ethology. 1999;105:619-636.

51. Price E., Feistner AT. Food sharing in lion tamarins: tests of three hypotheses. Am J Primatol. 1993:211-221. 
587

588

589

590

591

592

593

594

595

596

597

598

599

600

601

602

603

604

605

606

607

608

609

610

611

612

613

614

615

616

617

618

619

620

621

52. Brown GR, Almond REA, Bates NJ. Adult-infant food transfer in common marmosets: an experimental study. Am J Primatol. 2005;65(4):301-12. doi:10.1002/ajp.20117.

53. Terkel J. Cultural transmission of feeding behaviour in black rats. In: Heyes CM, Galef BG, eds. Social Learning in Animals The Roots of Culture. San Diego: Academic Press; 1996:17-47.

54. Galef BG, Giraldeau L-A. Social influences on foraging in vertebrates: causal mechanisms and adaptive functions. Anim Behav. 2001;61(1):3-15. doi:10.1006/anbe.2000.1557.

55. Meinertzhagen R. The education of young ospreys. Ibis (Lond 1859). 1954:153-155.

56. Caro TM. Effects of the mother, object play, and adult experience on predation in cats. Behav Neural Biol. 1980;29(1):29-51.

57. Caro TM. The effects of experience on the predatory patterns of cats. Behav Neural Biol. 1980;29(1):1-28.

58. Caro TM. Short-term costs and correlates of play in cheetahs. Anim Behav. 1995;49(2):333-345. doi:10.1006/anbe.1995.9999.

59. Thornton A, McAuliffe K. Teaching in Wild Meerkats. 2006;313:228-229. doi:10.1126/science.1128727.

60. Raihani NJ, Ridley AR. Experimental evidence for teaching in wild pied babblers. Anim Behav. 2008;75(1):3-11. doi:10.1016/j.anbehav.2007.07.024.

61. Radford AN, Ridley AR. Recruitment calling: a novel form of extended parental care in an altricial species. Curr Biol. 2006;16(17):1700-1704. doi:10.1016/j.cub.2006.06.053.

62. Emery NJ, Clayton NS. Effects of experience and social context on prospective caching strategies by scrub jays. Nature. 2001;414(6862):443-446. doi:10.1038/35106560.

63. Bugnyar T, Heinrich B. Ravens, Corvus corax, differentiate between knowledgeable and ignorant competitors. Proc Biol Sci. 2005;272(1573):1641-1646. doi:10.1098/rspb.2005.3144.

64. Tomasello M, Call J, Hare B. Chimpanzees understand psychological states - the question is which ones and to what extent. Trends Cogn Sci. 2003;7(4):153-156. doi:10.1016/S13646613(03)00035-4.

65. Franks NR, Richardson T. Teaching in tandem-running ants. Nature. 2006;439(7073):153. doi:10.1038/439153a.

66. Clutton-Brock TH, Gaynor D, McIlrath GM, et al. Predation, group size and mortality in a cooperative mongoose, Suricata suricatta. J Anim Ecol. 1999;68(4):672-683. doi:10.1046/j.1365-2656.1999.00317.x.

67. Clutton-Brock TH, Brotherton PN, Russell AF, et al. Cooperation, control, and concession in meerkat groups. Science. 2001;291(5503):478-481. 
68. Brotherton PNM, Clutton-Brock TH, Riain MJO, et al. Offspring food allocation by parents and helpers in a cooperative mammal. Behav Ecol. 2001;12(5):590-599. reproductive potential of offspring in cooperative meerkats. Proc R Soc B Biol Sci. 2007;274(1609):513-520. doi:10.1098/rspb.2006.3698.

627

70. Doolan S, Macdonald D. Diet and foraging behaviour of group living meerkats, Suricata 628

73. Frith CD, Frith U. Theory of mind. Curr Biol. 2005;15(17):644-645.

74. Heyes CM. Anecdotes, training, trapping and triangulating: do animals attribute mental states? Anim Behav. 1993;46:177-188.

75. Povinelli DJ, Vonk J. Chimpanzee minds: suspiciously human? Trends Cogn Sci. 2003;7(4):157-160. doi:10.1016/S1364-6613(03)00053-6.

76. Penn D, Povinelli DJ. The comparative delusion: the behaviorstic/mentalistic dichotomy in comparative theory of mind research. In: Metcalfe J, Terrace HS, eds. Agency and joint attention.Vol 3. Oxford: Oxford University Press; 2013:62-81. doi:10.1093/acprof:oso/9780199988341.001.0001.

77. Heyes CM. Theory of mind in nonhuman primates. Behav Brain Sci. 1998:101-148.

78. Lurz RW. If chimpanzees are mindreaders, could behavioral science tell? Toward a solution of the logical problem. Philos Psychol. 2009;22(3):305-328. doi:10.1080/09515080902970673.

79. Ostojic L, Cheke LG, Shaw RC, Legg EW, Clayton NS. Desire-state attribution: Benefits of a novel paradigm using the food-sharing behaviour of Eurasian jays (Garrulus glandarius). In Press. Commun Integr Biol. 7(1):e34412.

80. Dickinson A, Balleine B. Motivational control of goal-directed action. Anim Learn Behav. 1994;22(1):1-18. doi:10.3758/BF03199951.

81. Dickinson A, Balleine B. Motivational Control of Instrumental Action. Psychol Sci. 1995;4(5):162-167.

82. Cheke LG, Clayton NS. Eurasian jays (Garrulus glandarius ) overcome their current desires to anticipate two distinct future needs and plan for them appropriately. Biol Lett. 2012;8(2):171-175. doi:10.1098/rsbl.2011.0909. 
83. Ostojić L, Shaw RC, Cheke LG, Clayton NS. Evidence suggesting that desire-state attribution may govern food sharing in Eurasian jays. Proc Natl Acad Sci U S A. 2013;110(10):4123-4128. doi:10.1073/pnas.1209926110.

84. Ostojić L, Legg EW, Shaw RC, Cheke LG, Mendl M, Clayton NS. Can male Eurasian jays disengage from their current desire to feed the female what she wants? Biol Lett. 2014.

85. Van Boven L, Loewenstein G. Social projection of transient drive states. Pers Soc Psychol Bull. 2003;29(9):1159-1168. doi:10.1177/0146167203254597.

86. Sommerville J a, Bernstein DM, Meltzoff AN. Measuring beliefs in centimeters: private knowledge biases preschoolers' and adults' representation of others' beliefs. Child Dev. 2013;84(6):1846-1854. doi:10.1111/cdev.12110.

87. Apperly IA, Carroll DJ, Samson D, Humphreys GW, Qureshi A, Moffitt G. Why are there limits on theory of mind use? Evidence from adults' ability to follow instructions from an ignorant speaker. QJ Exp Psychol (Hove). 2010;63(6):1201-1217. doi:10.1080/17470210903281582.

88. Kamil AC. Eurasian jays predict the food preferences of their mates. Proc Natl Acad Sci U S A. 2013;110(10):3719-3720. doi:10.1073/pnas.1300515110.

89. Taylor AH. Corvid Cognition. WIREs Cogn Sci. 2014;5:361-372. doi:10.1002/wcs.1286.

90. Hattori Y, Leimgruber K, Fujita K, de Waal FBM. Food-related tolerance in capuchin monkeys (Cebus apella) varies with knowledge of the partner's previous foodconsumption. Behaviour. 2012;149(2):171-185. doi:10.1163/156853912X634124.

91. Scheid C, Schmidt J, Noë R. Distinct patterns of food offering and co-feeding in rooks. Anim Behav. 2008;76(5):1701-1707. doi:10.1016/j.anbehav.2008.07.023.

92. Paz-Y-Miño C G, Bond AB, Kamil AC, Balda RP. Pinyon jays use transitive inference to predict social dominance. Nature. 2004;430(7001):778-81. doi:10.1038/nature02723. 